\title{
DELIBERATIVE MONETARY VALUATION: IN SEARCH OF A DEMOCRATIC AND VALUE PLURAL APPROACH TO ENVIRONMENTAL POLICY
}

\author{
Alex Y. Lo \\ Griffith University and Vienna University of Economics and Business
}

\begin{abstract}
Clive L. Spash
Vienna University of Economics and Business and Norwegian University of Life Sciences
\end{abstract}

\begin{abstract}
The use of deliberative methods to assess environmental values in monetary terms has been motivated by the potential for small group discussion to help with preference formation and the inclusion of non-economic values. In this review, two broad approaches are identified: preference economisation and preference moralisation. The former is analytical, concentrates upon issues of poor respondent cognition and produces a narrow conception of value linked to utilitarianism. The latter emphasises political legitimacy, appeals to community values and tends to privilege arguments made in the public interest. Both approaches are shown to embrace forms of value convergence, which undermine the prospects for value pluralism. As a result exclusion and predefinition of values dominates current practice. In order to maintain democratic credentials, the importance attributed to monetary value needs to be left as an open question to be addressed as part of a process determining an "agreement to pay". To this end we identify a discourse-based approach as a third way consistent with the democratic and value plural potential of deliberative monetary valuation.
\end{abstract}

Keywords. Deliberative democracy; Ecological economics; Environmental valuation; Ethics; Monetary valuation; Public policy; Stated preferences; Value pluralism

\section{Introduction}

Deliberative monetary valuation (DMV) combines economic and political processes to value the environment (Spash, 2007). Participating individuals form small groups to share information and raise concerns about a proposed environmental change. The procedure of quantifying environmental values in monetary terms is preceded by a dialogue or deliberation amongst the valuing agents. They are typically supported and guided by practitioners or researchers and given opportunities to discuss prior to stating a willingness-to-pay (WTP) ${ }^{1}$. The value obtained is meant to be of potential use in project appraisal, cost-benefit analysis (CBA) or other formal decision processes. Design varies but deliberative sessions usually last one to two hours and may be repeated over several days. 
From the first theoretical discussions over deliberation and economic valuation, in the 1990s, the method attracted attention from a range of disciplinary experts. These included not only those from economics (Brown et al., 1995; Spash, 2001), but also researchers from decision science (Gregory et al., 1993), politics (Jacobs, 1997; Ward, 1999), human geography (Clark et al., 2000) and applied philosophy (Sagoff, 1998; O’Neill, 2001). Debates, workshops and research have also involved various disciplinary mixes. As a result, different perspectives on what constitutes the aims of DMV has led to some strongly divergent practice.

In general, DMV has developed as a response to problems associated with environmental value elicitation using stated preference methods; that is the contingent valuation method (CVM) and choice experiments. In technical terms, within environmental economics, these problems are regarded as including lack of prior preferences and poor understanding of environmental change on the part of valuing agents. Group processes are expected to enable information sharing, provide opportunities for effective preference construction and even to overcome an individuals' bounded rationality (Gregory and Slovic, 1997). This is to be achieved by exposing participants to a variety of perspectives and value positions held by others.

Increasingly, ecological economists have shown interest in adopting aspects of public deliberation in seeking alternatives to environmental CBA, stated preference methods and benefit transfer (Spash et al., 2005; Spash and Vatn, 2006; Söderbaum and Brown, 2010). The aim has been to develop approaches for integrating diverse values and so improve public participation and representation in policy initiatives (Spash, 2001). This has led to exploring the potential for a deliberative economics (Norgaard, 2007; Zografos and Howarth, 2008). From this perspective the problems, which can potentially be addressed by DMV relate to the exclusion of non-utilitarian ethical systems (e.g. rights-based thinking) and non-economic motives for valuing the environment (Spash, 2000a, 2006).

Promoting public reasoning, rather than individual preference satisfaction, as a basis for collective decisions, raises the prospect of a transformative and moralising experience (Niemeyer and Spash, 2001; Spash, 2007). This shows DMV appealing to the political sciences and in particular the theory of deliberative democracy (Cohen, 1989; Dryzek, 1990; Bohman, 1996; Gutmann and Thompson, 1996; Dryzek, 2000). That theory arose in the early 1990s leading to what has been called a "deliberative turn" in democratic theory (Dryzek, 2000, p. 1). This has at its core the imperative of mutual justification of the positions held by those subject to the consequences. Democratic legitimacy is sought by participation in an open, inclusive and reciprocal dialogue among free and equal citizens.

Theoretical attempts to merge participatory deliberative methods with monetary valuation soon followed the deliberative turn (Jacobs, 1997; Sagoff, 1998). The body of literature on DMV has grown rapidly especially in recent years (Howarth and Wilson, 2006; Macmillan et al., 2006; Urama and Hodge, 2006; Powe, 2007; Spash, 2007, 2008a; Álvarez-Farizo et al., 2009; Dietz et al., 2009; Ito et al., 2009; Jorgensen, 2009). Unfortunately, the proliferation may be more of a deliberative wash than substantive change. Some DMV applications have been criticised for engaging in rhetorical use of deliberative methods to repair and revalidate stated preference methods in an "economic valuation as usual" approach (Spash, 2008a; Jorgensen, 2009). Indeed, building DMV upon the neoclassical economic tradition appears unpromising for reasons explored later in this paper.

There are also doubts as to the appropriateness of deliberative approaches in providing valid benefit estimates for economic analysis. A range of concerns have been raised including: statistical representation and stability of responses (Powe, 2007), failure to deal with trade-offs (Orr, 2007) and WTP question format (Aldred, 2005). DMV is also questioned on normative grounds for unnecessarily reducing plural values into a single metric, which invariably violates the incommensurability of ethical values $^{2}$ (Vatn, 2005; O'Neill, 2007). That is, there is serious doubt as to whether justifying DMV results as an economic value requires excessive qualification and manipulation of environmental values. An unresolved issue is then how far DMV can and should be seen as an economic tool. This then raises concerns about the purposes of DMV and the nature of monetary expressions.

Journal of Economic Surveys (2013) Vol. 27, No. 4, pp. 768-789

(C) 2012 John Wiley \& Sons Ltd 
In addition to exploring economic concerns, we show that some of the political arguments for DMV are equally fraught with contradictions. We attempt to substantiate that critique by elaborating on a larger body of literature in light of a theory of deliberative democracy. Nevertheless, the result is not to reject DMV completely, but rather to redeem it by highlighting the deeper implications of appealing to deliberative democracy.

The next section briefly provides the background to and theoretical development of DMV. Section 3 introduces our categorisation of existing DMV practice into two approaches, namely, preference economisation and preference moralisation. The methodological contrast of these two approaches are then brought into focus. Section 4 builds on this by conducting a critical review with reference to representative studies, which reveals the perceived meanings attributed by expert researchers/practitioners to the valuation inquiry and elicited values. This raises the role of enforcing impartiality as public interest and employing utilitarianism, both of which are shown to reduce the validity of DMV as a means of probing and articulating plural values. Section 5 turns to the role played by experts in crowding-out deliberative democratic principles. An alternative approach to DMV is then proposed in Section 6. This aims to avoid some of the identified pitfalls and regain the essence of an original driver for DMV, namely to provide a more democratic and value plural institution for use in environmental public policy. The paper concludes by drawing implications for the emerging area of deliberative economics.

\section{From Disciplinary Failure to Multidisciplinary Synthesis}

The development of DMV by multiple disciplines has contributed to variety in conceptual models. The variations can be broadly attributed to two widely discussed limitations of stated preference approaches to environmental valuation. The first is based upon a debate held within economics and the second a more broadly defined set of critiques involving non-economists.

We refer to the first set of limitations, or failures, as the internal critique. The basic concern is that individuals confront too difficult a task when being asked to value an environmental change in monetary terms during a relatively short interview or survey (e.g. 15 to 20 minutes). Typical arguments are the lack of time to reflect or engage in arbitrage (Macmillan et al., 2002, 2006; Robinson et al., 2009) and respondents' inadequate cognitive capacity to understand the welfare trade-offs being requested under such circumstances (Gregory and Slovic, 1997; McDaniels et al., 2003). Individuals who are as a consequence classified as giving "irrational" responses are regarded as falling short of the standard economic assumptions underpinning stated preference approaches. Bateman et al. (2008, p. 139) propose that these individuals need to gain repetitive experience of the "operating rules of the contingent market" through a "learning design contingent valuation" to elicit theoretically consistent values. Among practitioners expressing such positions there is a belief that people should behave more in accord with economic theory, that is, as homo economicus.

A second area of concern is what we term the external critique (i.e., outside mainstream orthodox economics). This identifies stated preference approaches as restricting the type of values that an individual is permitted to express. For example, respondents may be forced to act as consumers (Sagoff, 1988), or those adopting rights-based rationales may be treated as protestors or expressing irrational lexicographic preferences (Spash, 2000b, 2008b). Under this critique, stated preference approaches are criticised for overlooking concerns about procedural justice, non-utilitarian ethics and the role of social norms, because they are built upon the assumption of monetary commensurability (Jorgensen et al., 2001; Spash et al., 2009). Standard economic assumptions then fail to properly capture the values held by individuals concerning a collective choice about the environment. There is a belief amongst DMV advocates expressing such positions that economics should embrace plural values or be qualified by alternative values. 
Table 1. Forms of Value Expression in DMV.

\begin{tabular}{lll}
\hline \hline & \multicolumn{2}{c}{ Terms in which payment specified } \\
\cline { 2 - 3 } Value provider & Individual (disaggregated value) & Social (aggregated value) \\
\hline Individual in a group setting & Charitable contribution & $\begin{array}{l}\text { Expressed social WTP/WTA } \\
\text { Group }\end{array}$ \\
\hline
\end{tabular}

Source: Spash (2007, 2008a).

Thus DMV is being justified in two contrasting ways: one questioning the capacity of individuals, and the other questioning the economic frame. Those practitioners who put more weight on people's limited cognitive abilities tend to run DMV as a tutorial or educational workshop to improve the face validity of their results. Those who regard values as being excluded emphasise institutional design, procedural fairness and the articulation of alternative ethical approaches. This is not necessarily a sharp dichotomy and as will be shown there are some shared basic perspectives. However, we believe the distinction is insightful and helps understanding of the literature.

This distinction is additional and complementary to the process based value classification of DMV studies, shown in Table 1, presented by Spash (2007, 2008a). Spash explains social value under standard stated preference techniques as typically being calculated by asking individually focused valuation questions of respondents, who decide as individuals. A DMV exercise designed to address the internal critique has no need to withdraw from this methodologically individualistic economic frame and the procedure of individual preference aggregation as representing social value. However, the group process involved is argued to make individual values into charitable contributions. Such a form of methodological individualism could also be maintained while deriving an aggregate value or an expressed social WTP/WTA directly from valuing agents; although the result would diverge from economic welfare surplus measures.

In contrast, a DMV addressing the external critique is likely to appeal to group procedures and break with such methodological individualism. Influenced by the idea of deliberative democracy, the process requires that individuals openly communicate with each other. Standard stated preference practice is called into doubt and replaced by participatory procedures, which include group decisionmaking. This leads to either a fair price or an arbitrated social WTP/WTA, depending upon whether the value produced is at an aggregate or individual level. This variety in problem definition allows a clear distinction to be drawn in terms of the form of monetary outcome favoured by different DMV advocates (see Spash, 2008a).

However, the earlier theoretical explorations of DMV fail to make such clear distinctions. In fact, some seek to synthesise different intellectual traditions to establish an aggregative enterprise. Wilson and Howarth (2002, p. 432), for example, see DMV as a unifying project and suggest that it is "derived from a convergence of arguments from economics, social psychology, decision science and political theory". Yet the competing conceptions about the role of the valuing agents (the public or stakeholders) and the inquirer (scientists or social scientists) are not explored. This neglects the conflict between the traditional classification of orthodox economics and social psychology as conducting a 'positivist' scientific discourse, whereas politics and ethics are regarded as 'normative'. The former tends to presume the individual to be an object for scientific study, the latter regards the individual as a self-defining subject within a social process. 
Even within the supposedly positivist disciplines of social psychology and orthodox economics the interdisciplinary cooperation required for a unified form of DMV is far from straightforward. Economics has an essentially static model of human behaviour based upon the assumption that an individual has both pre-existing preferences and perfect information; they act as rational utility maximising agents. Social psychology has a process model where the emphasis is upon how beliefs and attitudes are formed or learnt and how information is acquired; agents are complex and fallible.

Another problem is the questionable assertion that public deliberation, being a political activity, is inherently conducive to value pluralism, because individuals are exposed to a wide range of viewpoints (Jacobs, 1997; Howarth and Wilson, 2006; Vatn, 2009). A pluralistic process certainly recognizes and seeks to maintain multiple ways of valuing in contrast to the monism of neoclassical economics. However, monism is not absent from political theory or philosophy. Some deliberative democrats are then open to criticism for advancing a narrow conception of value (see Dryzek, 2000) and organising participatory processes that unduly close-down alternatives (Stirling, 2006). History has shown that participatory engagement does not guarantee value pluralism nor tolerance of alternative viewpoints.

The literature on DMV can then be explained in terms of two key aspects. First, there are distinct and contrasting approaches arising from those primarily concerned with internal critiques as opposed to those pre-occupied with external critiques. Secondly, there are identical underlying methodological problems facing both because of some shared theoretical positions. We begin, in the next section, by further exploring the distinction between contrasting approaches, before turning, in Section 4, to an explanation of the literature in terms of some rather problematic common organising principles.

\section{Two Contrasting Approaches Seeking Value Convergence}

\subsection{Preference Economisation}

Decision scientists and some environmental economists favour an analytical form of deliberation, which leads to preference construction in accordance with neoclassical economic theory. The primary objective of DMV is then to ease respondents' cognitive burdens. Adequate information and time to think and discuss are provided to tackle what are regarded as the problems arising from individuals' limited imaginations and calculating abilities. A behavioural psychological literature is called upon to support the case that individuals do not hold informed, stable and pre-existing preferences (Peterson et al., 1988; Kahneman and Knetsch, 1992; Kahneman et al., 1999), and often fail to meaningfully express their entangled values (Gregory et al., 1993; Gregory and Slovic, 1997). Environmental valuation can then be seen as an excessively demanding task. Protest and 'irrational' responses are explained in terms of cognition problems resolvable by preference engineering (Gregory et al., 2005; Hanley and Shogren, 2005; Bateman et al., 2008). Practitioners then aim to implement a process whereby preferences are clarified, constructed and articulated in a cognitively rational manner. Strictly structured, informative group discussion is then regarded as a method for lessening the impact of impediments to WTP elicitation, such as bounded rationality.

The underlying diagnosis makes no explicit philosophical arguments. Full commitment to this scientific-behavioural view protects some fundamental economic principles, including value monism. DMV is then devised to ensure rational choice by correcting ill-constructed preferences and embedding value articulation in orthodox economic logic.

Respondents may, for example, be guided through a structured thinking process designed in accordance with multi-attribute utility theory (MAUT; Gregory et al., 1993; Gregory, 2000; Gregory and Wellman, 2001). Under this formulation, valuing agents express their preferences for each attribute by assigning weights. The results can then be used as a basis for translating environmental values into equivalent money terms. 
Another stream of thought simply supplements stated preference approaches with additional information, time, opportunities to share knowledge and occasionally a citizen-type frame of reference (Macmillan et al., 2002; Robinson, 2002; Philip and MacMillan, 2005; Álvarez-Farizo and Hanley, 2006; Macmillan et al., 2006; Urama and Hodge, 2006; Álvarez-Farizoa et al., 2007; Lienhoop and MacMillan, 2007; Álvarez-Farizo et al., 2009; Robinson et al., 2009). A modified exchange value is intended, and deliberative engagement is minimal. However, the process actually produces charitable contributions rather than economic welfare measures (Spash, 2008a). This divergence is neglected because of the way in which the valuation problem is framed as improving stated preference validity.

Cognitive issues are considered as central to the preference economisation approach. The starting point is the individuals' inability to articulate values in monetary terms, rather than inherent incommensurability. 'Irrational' behaviours commonly documented in valuation studies are relegated to a first-party problem, that is, it is the individuals who fail. Uninformed respondents need professional guidance to clarify values and this is supported by additional information and time for thinking. Moral dispute over values is irrelevant or unimportant because everything is assumed to be reducible to some form of cognitive difficulty. There is no need to subvert the economic frame; only better science is needed, that is, decision analysis and consistency with economic theory.

Valuing agents cannot then be left to themselves. For example, Gregory and associates are highly sceptical of unaided value articulation ${ }^{3}$. They offer a strictly structured approach involving reengineering of the valuing agents' mindset in accordance with a given evaluative model (Gregory, 2000; Gregory et al., 1993; Gregory and Slovic, 1997; McDaniels et al., 2003). The evaluation tasks are designed to streamline personal heuristic reflection supported by group discussion. The process mimics what is regarded as a 'natural' human thought process in order to enable participants to think rationally about their objectives and the benefits and consequences associated with alternatives. Environmental disputes are believed to arise from "differences in the believability or interpretation of facts" rather than underlying values (Gregory, 2000, p. 157). The evaluation is thus concentrated on clarification of facts and evidence. This requires that the values expressed must demonstrate an 'evidential basis' (Failing et al., 2007). The DMV group discussion then revolves around various functional, fact-based value dimensions constructed to allow explicit comparison of benefits and costs (Gregory, 2000; McDaniels et al., 2003). Subjective values must be properly articulated, using an objective scale, to be considered in the process.

Moreover, values are assumed to be quantifiable and substitutable which allows their translation into money values. Gregory (2000) and Gregory and Slovic (1997) suggest that the perceived importance of, say, preservation of old-growth forests, can be measured by the respondents assigning 'value points' to critical habitat. Value points are also assigned to a specified amount of money. This allows translation of the value points attached to forest preservation into money. The procedure operates under the assumptions that the valued items are divisible, without affecting their perceived importance, and the values attached to them are commensurable.

A difficulty with this approach is that some moral and cultural values are limited to qualitative forms of expression such as social actions or narratives. The procedure of quantification and translation via a common unit reifies subjective values in a controlled setting that is far from the contexts where they generate meaning. This comparative framework is itself value laden, typically embodying an assumption that all evaluative dimensions are subject to utilitarian trade-offs (Stirling, 2006). It threatens to distort the original forms of value expression in favour of its own framing. Comparing values on a scale, which is by design favourable to one specific value perspective is in contradiction of value pluralism but common amongst orthodox economists.

Indeed practitioners employing preference economisation DMV are pre-occupied with various orthodox economic perspectives (Macmillan et al., 2002; Alvarez-Farizo and Hanley, 2006; Urama and Hodge, 2006; Alvarez-Farizo et al., 2007; Alvarez-Farizo et al., 2009). Their purpose in conducting DMV is stated as achieving a more robust exchange value. In most cases, the core valuation tasks are 
framed as a consumer-type decision-making process. For example, Gregory (2000) uses the market analogy of a car purchase as a valuation example for participants to think about. One outcome of such framing is the exclusion of responses falling outside the market frame. Such responses become protests and include those classified as failing to genuinely consider the required economic trade-offs, because such refusals to trade confound standard economic explanations (Spash, 2008a).

The valuation attempts of various economic practitioners are also oriented to an information-deficit model. Robinson (2002, p. 97) employs a citizens' jury to address the "problems of information bias" observed in conventional valuation studies. Likewise Urama and Hodge (2006) are satisfied that their educational participatory workshop overcomes the 'challenge' of information provision. The rhetoric bears some resemblance to Gregory's strategy of easing cognitive burdens by making information provision and learning more efficient. The whole DMV experiment is then designed to feed the valuing agents with adequate information and encourage personal reflection on a set of researcher/practitioner selected facts. The role for group discussion becomes trivial-helping participants "to learn what they want to know" for making rational decisions (Macmillan et al., 2002, p. 57). The processes are then in line with Gregory et al.'s (1993) suggested student tutorial analogy and Bateman et al.'s (2008) "learning design contingent valuation".

The preference economisation approach emphasises value elicitation at the individual level. Group discussion supports individuals in making their choice rather than the other way round. This approach seeks to induce instrumental rationality by focusing participants on the possible practical consequences of their prospective choice, and enforce an intra-personal integration of values by making individuals more conscious and informed of the relevant knowledge relating to that choice. Furthermore, the approach is sceptical of citizen empowerment; it appears somewhat manipulative and far from the deliberative democratic model. Potential for debate on fundamental values is minimal. Public values are sought from the focused thinking on public interests, but the desire is for deliberative WTP in terms of a neoclassical economic construct. This approach nurtures rational economic men.

\subsection{Preference Moralisation}

DMV theorists from a wide range of disciplines identify the principal problems of environmental valuation as inadequate opportunities for expressing values and inappropriate attention to non-economic considerations, including social norms, rights and procedural fairness (Vatn and Bromley, 1994; Clark et al., 2000; Jorgensen et al., 2001; O'Neill, 2007; Spash et al., 2009). Various attempts have been made to draw on political theories to establish more ethical, open and fairer value articulating institutions (VAI) (O'Hara, 1996; O'Neill, 2007; Douai, 2009; Vatn, 2009). Of particular interest to this group has been the theory of deliberative democracy rooted in Habermas's discourse ethics and other political traditions (Cohen, 1989; Bohman, 1996; Bohman and Rehg, 1997; Dryzek, 2000). The theory entails exchange between competing discourses through authentic communication among free and equal citizens in a non-coercive fashion (Dryzek, 1990, 2000, 2011). Citizens must equip their value claims with reasons and justify these to others in the search for fair terms of social cooperation. Political legitimacy is sought from justification to, and reasoned acceptance by, those who will have to live with the consequences. Reciprocal understanding is regarded as key to producing fair outcomes.

Preference moralisation DMV follows on from this tradition by giving credence to legitimacy issues, civic engagement and social learning (Brown et al., 1995; Jacobs, 1997; Sagoff, 1998; Ward, 1999; Niemeyer and Spash, 2001; Wilson and Howarth, 2002; James and Blamey, 2005; Howarth and Wilson, 2006; Spash, 2007, 2008a). Participants are typically given more freedom in agenda setting and calling expert witnesses than under preference economisation. After hearing expert presentations and discussions, participants provide a WTP estimate in the form of a value for society or individual contribution. In either case, some form of group agreement is required. Although minority positions are 
not excluded a priori, in general aggregated values are sought leading to an arbitrated social WTP/WTA (see Table 1). A democratic process, and not merely an economic estimation, is sought.

A social process is therefore constructed in which participants bring forth a variety of perspectives, and debate and reflect upon their preferences. There is a strong emphasis on the interactive aspects of DMV. Participants are expected to exercise the virtue of reciprocity and appeal to the "force of the better arguments" in a group process, often with the aim of consensual outcomes. Value convergence under preference moralisation is couched in terms of public interest (e.g. Brown et al. 1995; Sagoff, 1998; Ward, 1999; Wilson and Howarth, 2002). This approach actively pursues collective reflection on public interests beyond personal considerations.

There is then a thread of argument that deliberation should be limited to 'We' perspectives (Vatn, 2005, pp. 360-361). For example, Sagoff (1998) argues against the usual practice in stated preference studies of using a design aimed at eliciting consumer preferences based upon 'I' perspectives. Instead, "a deliberative, discursive, jury-like research method emphasising informed discussion leading toward a consensus based on an argument about the public interest" is recommended (Sagoff, 1998, p. 213). In such a context, valuing agents might be asked to deliberate without emphasising the individual welfare effects. Yet, to ask all participants in a DMV exercise to stop thinking as consumers is to attempt to silence a dominant societal conflict and value perspective. That is, to impose such public interest frames might unrealistically remove the fundamental conditions of moral disagreement that deliberation is designed to address. Respondents may reasonably protest against the imposition of an exclusive citizen frame. Silencing voices does not free a theory from value conflict, irrespective of the type of values crowded out.

Sagoff (1998), however, has ignored the fact that individuals play the dual role of citizens and consumers simultaneously-market choices are also political choices. Such a dichotomous distinction as citizen opposed to consumer is unrealistic and unnecessary. The 'I' and 'We' are integrally linked. The attempt to enforce 'We' perspectives can then prove highly problematic.

For example, Ward (1999) prohibits personal evaluations in a citizens' jury type approach: "Jurors are not asked to express their personal evaluations but their judgements about what environment quality is worth to society as a whole" (Ward, 1999, p. 79). Despite this, he then asks people to defend their personal evaluations and states that in a properly functioning citizens' jury: "jurors would be forced to defend their personal evaluations because others would use these as evidence for making their own collective evaluations under extended sympathy" (Ward, 1999, p. 91). The first statement renders the second logically redundant; if a participant is not allowed to express their personal evaluation they lose the grounds on which to defend it. Elsewhere in the paper Ward (1999) accepts that participants appeal to personal childhood memory when deliberating on heathland preservation. Unfortunately he then again contradicts himself by suggesting that participants should not be asked to express what the environment is worth to them as individuals (Ward, 1999, p. 91). Such authors appear to hold a highly ambiguous position with regard to the program being advocated for addressing value articulation by members of the public.

In general the aim of those advocating a preference moralisation approach is for consensus (Sagoff, 1998; Ward, 1999; Wilson and Howarth, 2002; Howarth and Wilson, 2006). They consider appeals to public interest as a means of overcoming differences between multiple comprehensive doctrines. Seeking consensus in the light of public interest is to seek moral support from a shared tradition that is assumed to be accepted by all parties involved. The feasibility of reaching consensus is then justified by assumption. However, moral disagreement often arises from precisely the absence of a shared tradition. People subscribe to different ethical views and follow different traditions, sometimes holding multiple positions and playing different societal roles simultaneously. As explored in the next section, the emphasis on public interest under preference moralisation is as problematic as the emphasis on utilitarianism in preference economisation, and both conflict with deliberative democratic principles. 


\section{DMV in Conflict with Deliberative Democracy}

Deliberative democracy affirms the role of mutual justification in pluralistic societies. Citizens are required to justify their value claims to others whom they affect. This demands that proposed value claims can be either accepted in light of reasoned reflection or rejected due to lack of merit. Such a position is challenged both by the impartialist public interest perspective common amongst preference moralisation approaches, and the prevalence of utilitarianism common amongst preference economisation approaches. Neither impartiality nor utilitarianism is, however, exclusive to either.

\subsection{Appeals to Impartiality and Impersonal Reasoning}

Impartiality demands that reasons given by deliberating individuals be acceptable to anyone who is similarly situated in morally relevant respects. Impartiality differs from reciprocity because it "demands that reasons be impersonal, requiring citizens to suppress or disregard their partial perspectives and individual projects" (Gutmann and Thompson, 1996, p. 54). Impartialist perspectives claim to be universally justifiable, entailing demonstration rather than justification. That is,

Impartialists can recognize the existence of moral disagreement ... but they regard it as a sign that moral reasoning has failed. At least one of the reasoners has erred, one or more have not carried the reasoning far enough, or else the problem itself is beyond the capacity of mortals to resolve. In the face of disagreement, impartiality tells us to choose the morally correct view and demonstrate its correctness to our fellow citizens, who, if they are rational, should accept it. (Gutmann and Thompson, 1996, p. 59)

Deliberating citizens must give reasons that would be justifiable from an impersonal perspective. The goal of this process is to establish a comprehensive moral view applicable to all. Other citizens are then bound to accept value claims as reasonable so long as they meet the moral doctrine. The function of deliberation then becomes demonstrating conformity of citizens to the moral doctrine. There is no requirement for mutual justification or debate.

The impartialist stance in DMV is common to the approaches falling under preference moralisation and in that context often linked to John Rawls' $(1971,1997)$ notions of justice and liberal democracy. For example, consider Brown et al.'s (1995) participant selection strategy. They link Harsanyi's impartiality to Rawls's (1971) 'original position', and argue for selecting participants who are capable of acting as agents of the larger public. In their 'value jury', facts are preceded by values as a deliberative focus. The recommended selection criteria include: being free from significant personal conflict of interest, willing and able to understand the issues and consider them objectively, and possessing an adequate level of maturity, intelligence and education (Brown et al., 1995, pp. 255-256). Representation of private or partial interests is completely excluded. The 'overriding objective' of their jury selection procedure is to avoid including those who have 'compelling personal interest': 'If a potential jurist's personal interest in the outcome is such that he or she is not likely to be willing or able to see and fairly consider the collective good, that person should be excluded' (Brown et al., 1995, p. 256). Because all the jurors are required to act as society's representatives and set aside personal interests, such a strategy can quickly become reason-blind (as discussed in relation to Ward in Section 3). That is, the basis for personal reasoning is lost.

Howarth and Wilson (2006) draw on Dryzek's $(1990,2000)$ discursive democracy, which emphasises contestation of discourse and condemns hierarchy-following the tradition of critical theory. However, their deliberative ideal of 'aggregation by mutual consent' appeals to a model of liberal democracy and again reference is made to Rawls (1971), amongst others. The Rawlsian approach hinges on a set of 'superior' political ideals functioning as a singular conception of values; acceptance of which weakens the need for moral deliberation by citizens (Bohman, 1996; Dryzek, 2000). This means a 
DMV approach calling upon Rawlsian ideals diverges from the critical strand, which challenges the idea of impartialist pre-accepted political ideals of universal appeal (Dryzek, 2000).

Downplaying partial interests by design undermines the arguments for invoking communicative reasoning. Yet, Wilson and Howarth (2002, p. 434) suggest that the most appropriate value articulating methodology is one that mirrors the Rawlsian "procedurally based public forum in which people are brought together to debate before making value judgments". Debating values is of little necessity if an overriding a priori reason is endorsed as a moral frame of reference. Authentic communication on a universally justifiable moral end is then redundant. Thus, James and Blamey (2005) are correct in pointing out that if their participants act fully as citizens operating behind the Rawlsian veil of ignorance, and have perfect knowledge of the relevant circumstances, limited representativeness is unproblematic. In such a case authentic representation of idiosyncratic perspectives would indeed be meaningless, because all participants are bound to relinquish their specific concerns to an impartial stance.

Arguments that must, a priori, be couched in terms acceptable to all citizens require only personal reflection (setting aside material self-interest) and self-reflective weighing-up of arguments. The Rawlsian public reason seeks potential acceptance from all members of society in light of liberal values. Because the reason is singular, it is destined towards a particular end wherever it is exercised; no interactive process is necessary to enable it to produce its conclusions.

As Dryzek (2000) notes, Rawls's (1997) theory of public reason could be undertaken by a solitary thinker, removing the need for participatory deliberation. Accordingly, the best individuals to exercise public reason would not be ordinary citizens, but intellectual elites. The participant selection strategy might, for example, follow that recommended by Brown et al. (1995) and conclude that the best combination of deliberators consists of trained professionals such as philosophers, economists, scientists and judges. Those lay citizens who have to live with the consequences of the decision would be excluded.

This would unambiguously violate the basic principles of deliberative democracy. Group deliberation is recommended by that theory precisely to introduce reasons that do not inherently possess universal appeal. Such reasons are then meant to be exposed to the possibility of being reasonably rejected. Unlike impartiality, the principle of reciprocity does not categorically exclude partial interests but necessitates actual deliberation.

\subsection{The Prevalence of Utilitarianism in DMV}

Another common organising principle is found amongst DMV preference economisation practitioners. That is, they place a strong emphasis on the psychology of information processing while operating under a preference utilitarian framework. This also reduces value pluralism. Thus, for example, some are keen to deny the validity of non-utilitarian responses, which are commonly found in conventional CVM studies (Spash, 2000a, 2006, 2008b). For example, Álvarez-Farize et al. (2007, 2009) seek the 'committed value of a citizen' but are reluctant to give credit to rights-based dimensions, which would undermine their utilitarian framework. Such perspectives are remaindered to being 'things' that fall under the valuers' economic preferences, although in an inevitably undefined way. Thus, they state: "the willingness to pay will not only include those things that favour individuals, but also those that favour the community" (Alvarez-Farize et al., 2009, p. 790).

Preference utilitarianism is implicit in the 'market stall' approach adopted by Macmillan et al. (2002, 2006), Philip and Macmillan (2005) and Lienhoop and Macmillan (2007). This is designed to lead people to think like consumers making purchase decisions in real markets. The approach is not called a citizens' jury because, as Macmillan et al. (2002) explain, it attempts to combine economic valuation with only the 'desirable features' of citizens' juries-presumably referring to 
the opportunities for information sharing. Non-economic considerations may then be precluded by removing the 'undesirable' features, which might cause them to be articulated.

Utilitarianism also clearly underlies the preference economisation approach of those analysts who are strongly committed to meeting pragmatic policy needs. Those practitioners theoretically grounding DMV in decision science attempt to make valuing agents thoroughly think through each key dimension of an issue and systematically construct and express their values. For example, Gregory and associates have applied the MAUT to a group CVM process (Gregory et al., 1993; Gregory, 2000). The outputs are mathematically combined to form a summary measure. The final calculation is based on 'expected utility' and a single utilitarian value structure is embraced. As Gregory et al. (1993, p. 188) state:

The eventual goal is to find a single hierarchy of values that all the shareholders [sic] can agree is complete. The values hierarchy must also be built with due concern for the form of the utility combination rule.

The nature of values as perceived by the decision science approach can be traced back to the value focused model sketched by Keeney (1992), in which values are understood as "what we want". However, debate is excluded under an orthodox MAUT approach, which replaces multi-criteria with a mono-criterion (Munda, 1995). Successful application of the approach requires 'tacitly asserting an individual dominant perspective and performance data set' (Stirling, 1997, p. 194). Unsurprisingly, Gregory and associates see little need for philosophical debate on the part of deliberating individuals, while alleging to democratise environmental assessment (Lo, 2011).

Clarification of values, rather than their justification, is the true purpose of such approaches. Group discussion is assigned a supplementary role, serving to raise participants' comfort and pool different evaluative judgements (McDaniels et al., 2003). This targets individuals' cognitive failure, requires the use of impersonal expressions of values and regards demonstration of benefits and costs as key. Thus, it fits squarely with the notion of impartiality. The whole project could be satisfactorily undertaken without any interpersonal deliberation.

Under preference moralisation, utilitarianism can also appear in an attempt to create social values combined with impartiality and impersonal reasoning. For example, the proposal by Ward (1999) is explicitly stated to be based on Harsanyi's utilitarianism. His normative ideal requires that individuals put themselves into others' shoes, extending their sympathy to others' interests. So long as a natural entity has interests that people would empathize with, a utility function can be ascribed to it. Such utility functions 'reflect the idea that it best serves interests if expected utility is maximized' (Ward, 1999, p. 90). Those interests admitted to citizen deliberation must be impersonal, as indicated by the preference for citizens to engage in the 'norms of impartial debate' (Ward, 1999, p. 79).

Utilitarianism offers a single inclusive end, utility, as the proper basis upon which to assess all moral claims. Adoption in a DMV process violates the principle of reciprocity by forcing citizens into a single hierarchy that they might legitimately reject. Utility maximization can then be seen as challenging the pursuit of deliberative democracy. That is, maximizing aggregate well-being leads to a neglect of partial and minority interest positions for which a reciprocal perspective must make room (Gutmann and Thompson, 1996).

In their preference moralisation approach, Howarth and Wilson (2006, p. 11) define the deliberative groups' maximum WTP for increased environmental quality as 'the level of W [group payment] for which the group would be indifferent between implementing the proposed project and maintaining the status quo'. They note that the WTP is based on a standard utility function that summarizes preferences, beliefs and moral judgments and is not limited to a person's individual well being or consumer preferences. Yet this does not preclude them from linking it to a maximization rule. Public deliberation is envisaged as a 'fair negotiating' process in which individuals engage in a search for maximisation of group well being. 
Minority interests, however reasonable, are always marginalized by the utility maximization rule. This means the imperative of reason-giving fails to function properly. If a deliberative group is instructed to make a decision that would guarantee maximisation of social utility, participants would only need an adequate supply of information and a process of corroboration, not reasoned debate. The moral role of DMV would be reduced to a pedagogical one emphasizing information exchange and clarification.

\section{Experts Crowding-out Deliberative Democracy}

On the premise that monetary value is inherently an economic construct, some practitioners appeal to the procedural benefits of public deliberation. As public deliberation can internalize equity issues and enhance procedural fairness, it is argued to be conducive to broadening the democratic basis of economic valuation (James and Blamey, 2005; Wilson and Howarth, 2002). On the same premise, others endorse public (or stakeholder) deliberation for allowing richer and higher-quality information content to meet higher economic standards (Gregory, 2000; Macmillan et al., 2002; Urama and Hodge, 2006). Many practitioners are sympathetic to both perspectives.

However, the premise is a pre-reason embedded in conventional stated-preference approaches that the analysts believe to be true and good for society. The analysts act as if themselves a deliberating agent, either implicitly or explicitly, and justify the premise a priori to the DMV participants. Constructed as an economic institution, monetary valuation of public goods always concedes trading-off morality given that trade-offs are part of the ideological norms of economics (Holland, 2002). Most importantly, this reveals grounds of reasoning which cannot be justified democratically.

The foregoing DMV models raise the prospect for value pluralism but resort to an accepted metaethical tradition in economics, namely utilitarianism, and/or require that participants impartially focus on public interest. Deliberation of this sort is subject to restrictions on reasoning. The prospects for value pluralism are questionable if researchers deliberately downplay some reasons by design or force those not normally used in a given context into the deliberative forum. Worse, some of the methodological preoccupations - such as excluding 'personal interest' - should be (but are not) open to debate. Research design builds upon philosophical foundations, which shape values. Debating values and beliefs but protecting the researchers' own from challenge is indefensible from a deliberative democratic viewpoint. This leaves the project of facilitating reasoned pluralism undefined and undefended.

Preference economisation strives to induce instrumental reasoning but removes attention from the need to reason. Cognitive failure amongst valuing agents is taken as the ultimate, overriding reason justifying the professionally aided deliberation. Other incompatible value positions have to be compromised to be considered. Firmly holding to the exclusively expert-led approach, Gregory and associates openly and firmly decline participants' autonomy in favour of a scientific deliberative design: 'the scope of their role falls well short of a license to redesign the process', 'one should never allow public involvement processes to actually set policy' (McDaniels et al., 1999, pp. 499-500). On this point the decision scientists and orthodox economists are united. Powe (2007, p. 166), an economist who favours a preference economisation DMV approach, believes that 'it may be considered inappropriate for the results from public consultation to directly determine the policy outcomes'. The economists' customary exclusion of 'irrational' responses also indicates a desire to protect some core of neoclassical economic beliefs about acceptable behaviour and appropriate values.

Yet, as we have seen, the alternative of an exclusive 'We' perspective under preference moralisation, whether utilitarian or other, is reason-blind and restrictive. Thus, the citizen-consumer dichotomy promoted by Sagoff $(1988,1998)$ is unhelpful for understanding the full range of environmental values (e.g. green consumerism), and the participant selection strategy preferred by Brown et al. (1995) seems likely to silence potential protestors. By restricting the deliberative space to considerations of public interest, such preference moralisation approaches are suspect for prejudging the problem at issue. 
A theory of DMV would be unsustainable if it prejudges the nature of the outcomes according to one of its candidate values, or its implied values are exempted from being challenged from within the deliberation by participants. Such prejudgement means practitioners act as both jury and judge, but shift between roles at various points. When designing and explaining the project, they act as jury to insert values; when defending this, they act as judge to override alternative interpretations or apply exemptions.

Although valuing agents are asked to reflect upon their preferences, there is little reflection on the part of practitioners. 'Practitioners do not evaluate the fairness of their procedures nor examine whether individuals believe that their own and others WTP is relevant to their conception of the problem at hand.' (Jorgensen, 2009, p. 251). The pursuit of pluralism is dubious if participants are led, according to the analysts' predisposition, to converge on values that ought to be openly discussed. There is no hope for fairness by unfairly expelling rivals.

Dietz et al.'s (2009) treatment may then offer guidance as being less restrictive than others. They consider environmental valuation as asking an essentially political question that is open to various philosophical conceptions of values. They carefully avoid predefining the deliberative outcome as a utilitarian construct. Deliberative WTP is seen as 'emerging from a social dialogue about, among other things, whether to define value in terms of a utilitarian calculus or in some other way' (Dietz et al., 2009, p. 330). Thus the extent to which the value articulating process should be framed in ways consistent with economics is an open question rather than to be taken for granted (Niemeyer and Spash, 2001; Jorgensen, 2009).

DMV can be designed to facilitate reasoned argumentation. A procedure of anonymous tabling of reasons was used both by Dietz et al. (2009) and by James and Blamey (2005). In the former, each participant wrote down a list of reasons in relation to global warming. They proposed one reason at a time and it was recorded and posted around the meeting room visible to all. The facilitator then asked for verbal comments on the listed reasons and prompted discussion. The process was repeated until all reasons were discussed. This approach enabled orderly argumentation over all concerns raised, and free articulation of reasons and their revision. It placed little restriction on the types of reason and forms of expression, making it conducive to communicative reasoning and less manipulative than other approaches. Dietz et al. (2009) concluded that the deliberating individuals acted like policy analysts by taking more consideration of the specific policy attributes.

\section{Choice Democratisation and the Discursive Ideal}

The literature reviewed reveals that the preoccupations of the researcher/practitioner can result in excessive intervention in the deliberative processes or even manipulation of outcomes (whether intended or unintended). Under preference economisation approaches individuals are required to strengthen their economic beliefs while under preference moralisation approaches they should convert their perspective toward a particular moral end. The proposed DMV processes appear to violate the requirements for value pluralism and multiple value expression. An alternative conceptualization is then needed.

A DMV model predisposed to a particular set of motivational criteria (e.g. maximising utility) is problematic. WTP has to be redefined to reflect the pluralistic and democratic nature of the DMV project. We therefore favour a 'discourse based approach', following O'Hara (1996, 2001), which is rooted in Habermasian discursive ethics (Habermas, 1984). Rather than recommending standard procedures we indicate key organising principles and requirements by which DMV processes can be evaluated in terms of their value pluralism. Core elements are summarised in Table 2, alongside those for preference economisation and moralisation approaches. We refer to this third DMV process as choice democratisation. 
Table 2. Conceptual Elements of the Three DMV Approaches.

\begin{tabular}{|c|c|c|c|}
\hline & $\begin{array}{c}\text { Preference } \\
\text { Economisation }\end{array}$ & $\begin{array}{l}\text { Preference } \\
\text { Moralisation }\end{array}$ & $\begin{array}{c}\text { Choice } \\
\text { Democratisation }\end{array}$ \\
\hline $\begin{array}{l}\text { Dominant a priori value } \\
\text { position }\end{array}$ & $\begin{array}{l}\text { Preference } \\
\text { utilitarian }\end{array}$ & $\begin{array}{l}\text { Rawlsian public } \\
\text { reason }\end{array}$ & Value pluralism \\
\hline Participant role & Consumer & Citizen & Any \\
\hline Aim of valuation & $\begin{array}{l}\text { True preference } \\
\text { revelation }\end{array}$ & $\begin{array}{l}\text { Social preference } \\
\text { revelation }\end{array}$ & Value articulation \\
\hline Aim of deliberation & $\begin{array}{l}\text { Information } \\
\text { transfer }\end{array}$ & Consensus seeking & $\begin{array}{l}\text { Argumentation/justification of } \\
\text { value claims }\end{array}$ \\
\hline Underlying principle & $\begin{array}{l}\text { Personal utility } \\
\text { maximization }\end{array}$ & $\begin{array}{l}\text { Impartial \& } \\
\text { impersonal } \\
\text { public interest }\end{array}$ & $\begin{array}{l}\text { Reciprocal understanding of } \\
\text { personal \& social interests }\end{array}$ \\
\hline Ideal participant & $\begin{array}{l}\text { Rational economic } \\
\text { man }\end{array}$ & Educated, informed & Articulate, informative \\
\hline $\begin{array}{l}\text { Expected cognitive } \\
\text { process }\end{array}$ & $\begin{array}{l}\text { Introspective } \\
\text { reflection }\end{array}$ & $\begin{array}{l}\text { Introspective } \\
\text { reflection }\end{array}$ & Inter-subjective understanding \\
\hline $\begin{array}{l}\text { Terms in which money } \\
\text { value expressed }\end{array}$ & $\begin{array}{l}\text { Charitable } \\
\text { contributions; } \\
\text { fair price }\end{array}$ & $\begin{array}{l}\text { Fair price; } \\
\text { expressed or } \\
\text { arbitrated social } \\
\text { WTP/WTA }\end{array}$ & $\begin{array}{l}\text { Fair price; arbitrated social } \\
\text { WTP/WTA }\end{array}$ \\
\hline
\end{tabular}

\subsection{DMV as a Second-Order Theory}

DMV faces the problem of being interpreted as a first-order theory. According to Gutmann and Thompson (2004), each first-order theory claims to be the single theory capable of resolving moral conflicts, but does so by rejecting rival theories and principles. For these theories, moral integration is an overarching concept. They assume that citizens subscribe to a particular moral belief (e.g. utilitarianism) or require them to change accordingly.

In contrast, deliberative democracy, as a second-order theory, is non-exclusive. Second-order theories are about other theories. They provide ways of dealing with the claims of conflicting first-order theories and govern their interaction. They make room for moral conflict to be resolved by some predetermined standards, which neither affirm nor deny moral principles expressed by first-order theories. Participants follow such standards or rules without the ends being predetermined. Thus, democratic deliberation does not necessarily aim to induce citizens to change their first-order values; it is rather aimed at encouraging diverse value positions to live with each other even if they are mutually incompatible (Gutmann and Thompson, 1996).

As far as irreducibility of plural values is concerned, a DMV framed by any first-order theory is doomed to failure. Deliberative democracy accepts solutions on the basis of reasoned differences and allows 'workable agreements' in which participants agree on a course of action for different reasons (Dryzek, 1990, 2000). An ideal deliberative process mediated by the principles of reciprocity should proceed with participants cultivating mutual respect for and recognition of each other's ethical perspectives, provided that they can be justified as reasonable. Participants are not rigidly required to agree on the principles of the alternative perspectives in specific, but accept them, if justified, as a legitimate basis of decision making. Mutual respect in reasoned argumentation is crucially important to this endeavour. 
Incommensurability of values cannot be removed by simply informing preferences or opening-up the valuation process to a variety of perspectives. The theory of deliberative democracy entails a reorientation of the interactive structure, and not merely of the substance of valuation. The epistemic status of monetary valuation has to be left open. The key is to downplay the privilege of any substantive value while allowing reasoned disagreement (Dryzek, 1990, 2000; Gutmann and Thompson, 1996, 2004). An ideal form of DMV should belong to no first-order theory and generate mutual agreement reached on the merit of each reasonable value claim.

\subsection{Habermasian Discourse}

Habermasian discourse is an idealised form of communicative action, in which differently situated individuals are engaged in a dialogue in an effort to search for common understandings exclusively by offering arguments that could induce reflective assent on the basis of their merits (Warren, 1995). The desired communication entails the virtues of reciprocity and mutual recognition. It depends on the capacity of deliberating individuals in checking, reflecting and bridging distinctive perspectives they hold, thereby identifying a generalisable domain in which these perspectives can make sense of each other. Behaviours are motivated by a cooperative intent in resolving conflicts and seeking policy recommendations from authentic group deliberation, and are communicatively coordinated through the discursive virtues, in contrast to preference economisation and moralisation which seek to systemically coordinate behaviours toward a singular moral domain.

In choice democratisation DMV, coordination by discourse precedes the measurement of WTP. The method primarily involves individuals collectively searching for and defining an institution acceptable for valuing the environment in monetary terms, rather than pricing it under a perfectly predefined institution. Values are construed broadly as reasons raised by individuals to justify a course of action, and the process of valuation is akin to seeking fair terms of cooperation on a payment to be levied either at a group or individual level. Epistemologically this institution is evolved from norms of dialogue and constructed through the medium of language; therefore it should be analyzed in such terms. In contrast to stated preference approaches, values should be articulated in DMV by focusing on the fabric of conversation and the psychodynamic between individuals. Analysis may involve an investigation of the deployment and structure of language in response to other participants' assertions or interpretations of reality during the course of deconstructing, defining and articulating requested monetary expressions, for example, using verbal protocol techniques. ${ }^{4}$

In discourse theory, speech has a motivational force, which can resolve conflict via shared social understanding (Warren, 1995). As discussion moves towards discourse the persuasive force of speech impacts on other's. Engaged participants become motivated cognitively to comprehend the relationships that situate them in a given controversy. They desire mutual understanding of their particular beliefs, concerns and situations. The veracity of this cognitive motivation can be assessed in terms of the degree to which there is sharing of subjective experiences between individuals, that is, inter-subjectivity.

\subsection{Inter-Subjectivity, Reason and Agreement}

Processes of value articulation that are inter-subjectively coordinated complicate the condition upon which an elicited deliberative WTP is conceptualized. The WTP may be undergirded by multiple and competing normative or epistemic dispositions. It should be understood as a collectively bound 'workable agreement' embodying the ideal of agreeing on ' $w$ hat is to be done while differing about why' (Dryzek, 1990, p. 43). A deliberative WTP, formed on the basis of reciprocity between two individuals who hold different moral beliefs, might then be influenced by at least two criteria: legitimacy and agreement. These are reflected in the contrast between willingness and agreement to pay.

Journal of Economic Surveys (2013) Vol. 27, No. 4, pp. 768-789

(C) 2012 John Wiley \& Sons Ltd 
An individual might be motivated towards a monetary agreement by their own interest, and/or recognition of the claim of others, in view of the legitimacy given by their cultural traditions and/or ethical beliefs. They might, however, still disagree in specific on the substantive principles held by the other. Based on mutual understanding and respect, this kind of agreement does not require or presume uniformity across participants or perfect agreement on norms but merely inter-subjectivity (Dryzek, 1990). Without subscribing or surrendering to each other's perspectives, the deliberating individuals might articulate WTP as a second-order agreement, which does not constitute trading-off their personal moral beliefs against others' (Gutmann and Thonpson, 1996, p. 93). The deliberative WTP would no longer entirely represent a money payment for common interest, because individuals might fail to consider the other's interest as acceptable in specific. It is better described as, at least partially, an 'agreement to pay'.

This contrasts with a person being willing to undertake an action (e.g. make a payment) to obtain or do something they consider as good or right. The evaluation could be undertaken by a solitary thinker given adequate information and a 'transaction' opportunity. The idea of willingness to pay does not capture the essence of the deliberative ideal of inter-subjectivity, as it is primarily motivated by and ends with one's own values.

On the other hand, a person might grant agreement on behalf of those whom they represent for something challenging to their own first-order values, so long as the reasons are compelling. This mutual justification process cannot be carried out by solitary thinking, but only by an interactive process pursuing inter-subjective understanding. Unlike willingness, engaging in some interpersonal connection or social relationship with those who are the objects of mutual justification is a necessary condition for agreement. A person might be willing to contribute to a course of action without other people's consent, but agreement always implies mutuality. The former is linked to personal interest (broadly defined as including utility, rights, or any other ideals considered desirable), whereas the latter also applies to causes outside of personal interests.

\subsection{Redefining Monetary Values}

Choice democratisation DMV is distinguished from conventional WTP studies by the requirement that its ethical legitimacy has to be validated not just in the privacy of one's mind, but also to the acceptance of outside parties, that is, other participants. This means only group-determined WTP/WTA make sense as the outcome of a democratic and pluralistic process, that is, fair price or arbitrated WTP/WTA. An appropriate assessment focus is then the quality of the agreement issued from the group processes and the strength of the motivation toward common understandings between group members.

Another property of choice democratisation DMV is that its substantive meaning is envisaged as contextually contingent. What it means is always seen as an empirical question, rather than a predefinable postulate. Pre-defining WTP/WTA according to standards exogenous to deliberation would imperil the pursuit of communicative rationality. The orthodox economic conception of values should be given no privilege, or the meaning would be dictated. The imperative of mutual justification demands that this and other conceptions be open to rejection in the valuation process. Participants are encouraged to bring forth a variety of values and beliefs and debate them based on their merits. Which set of values will contribute to or explain the outcome is difficult to predict, and undesirable to prejudge. The natural dynamic is largely unknown prior to deliberation and all value claims have the chance of being rejected. To give a universal definition to monetary outcomes under choice democratisation DMV is impossible and unnecessary.

Some have contended that there is no hope for the endeavour of rights and equity so long as a money value is assigned. For example, Vatn (2005, p. 361) points out that DMV as a VAI is based on a contradiction, because:

Journal of Economic Surveys (2013) Vol. 27, No. 4, pp. 768-789

(C) 2012 John Wiley \& Sons Ltd 
It mixes collective reasoning and consensus building over principles and norms with individual trade-off calculations. It combines a VAI based on capturing incommensurability with one that is focused on commensurability. It mixes a VAI directed towards the 'We' with one based on an 'I' perspective.

Vatn's $(2005,2009)$ ' $I$ ' versus 'We' critique is defensible if the valuation inquiry is entirely underwritten by a neoclassical economic framework. However, his arguments are undermined when communicative and economic rationalities are neither regarded as dichotomous nor mutually exclusive. The epistemic status of monetization is amenable to the rationality of the concerned VAI. Communicative rationality is the extent to which an action is characterized by reflective and intersubjective understanding of competent actors on values, beliefs and preferences (Habermas, 1984; Dryzek, 1990). As an inter-subjective discourse, it does not and should not preclude individual citizens from exercising utility maximization rules. Rejection of the dominance of orthodox economics should not be conflated with rejection of orthodox economic rationalisation by individuals. The political ideal requires individuals to question or defend the case for monetary valuation, but does not by definition accept or deny it on their behalf. On these grounds restricting public deliberation to 'We' perspectives and communitarian norms is also indefensible.

Valuing the environment in monetary terms is not inherently unacceptable on democratic grounds. For example, utility maximization rules and market rationality might be accepted upon mutual agreement among all the participants of a discursive process (Dietz, 1994). The assertion that such economic imperatives are invariably incompatible with the rationality of public deliberation effectively renders the deliberative rules exogenous to the communicative process from which political legitimacy is being sought. The aim should be to regulate economic rationality with communicative reasoning and employ a discursive design to preclude any manipulative or coercive treatment privileging a particular doctrine (O'Hara, 1996; Söderbaum and Brown, 2010). Making reason-giving processes open, free and critical appears more ethically appropriate than professionally guiding them along a route justified and rationalised by decision-science (i.e. the contrast between Dietz et al., 2009 and Gregory, 2000). The social meaning of assigning monetary values has to be set free.

That the openness of the democratic DMV methodology allows multiple potential ways of interpreting values may lead critics to claim the approach can only create ambiguity in policy recommendation. Clearly such ambiguity can be reduced by using more structured deliberative designs, but formalisation risks limiting the scope of deliberation and the range of values expressed (Lo, 2011). Policy-makers who seek to open-up debates on contested economic and environmental values should recognise that DMV does not primarily pursue accuracy of numeraire estimation but legitimacy of value articulation in circumstances of social disputation. Empowering and supporting deliberative groups in the appraisal of environmental change would go some way to address the democratic deficit in environmental policy. This could easily be extended to the use of DMV for the re-assessment, amendment, qualification, rejection or endorsement of monetary values generated from conventional valuation methods. Of course such democratisation of monetary valuation is a challenge to the existing technocracies employing environmental CBA and benefit transfer methods.

\section{Conclusions}

DMV should not be predefined as tied to any one value orientation or philosophy, otherwise it will soon fail to address incommensurability and value pluralism. Deliberative institutions cannot make incompatible value positions compatible, but they can help them live peacefully and respectfully together. As an institution, DMV has the potential to contribute to the social importance given to the act of valuing and any money values articulated. Meaning is assigned to monetary values through a process of cooperative engagement and is part of what is being sought by the deliberative institution.

Journal of Economic Surveys (2013) Vol. 27, No. 4, pp. 768-789

(C) 2012 John Wiley \& Sons Ltd 
There is no need to rigidly envisage the social act of paying as universally fixed or always being a trade-off.

DMV theories influenced by the critical strand of deliberative democracy do not simply seek the values of public goods from aggregating stated preferences. They call for an emphasis on intersubjectivity as much as the informational content of any value obtained. In this tradition, we argue for DMV to be re-conceptualized as a mutual agreement resulting from an interactive process involving the contestation of discourses. DMV should neither be taken as an extended form of CVM to validate economic doctrine on the basis of informative talks. There are sufficient reasons not to marry DMV to neoclassical economic valuation, nor any other single tradition. DMV theories and applications that privilege any single conception of values, or marginalise others by design, should be regarded as failing to fulfil the promise of choice democratisation.

The enemy of deliberative economics is not neoclassicism, but hierarchy of any kind. Countering the limitations of neoclassical economics appears to have led to encountering the limitations of decision science and liberal political philosophy. There are signs of granting privilege beyond redeeming the excluded. As a project aimed at broadening democracy this appears as unjustifiable. Deliberative economics as a demonstration of the political axiom, 'the force of the better arguments', must make all of its contributing theories redeemable. The cure for the ailments of public value theory is more democratic theory-in both its production and content. Deliberative principles apply to the subject of inquiry (the public or stakeholder) as well as the inquirer (researcher). Deliberative economics involves a critical discourse built upon a set of principles and norms to facilitate critical encounter and dialogue on equal footing. It requires more than a platform to express or reinforce viewpoints. Of more importance is the reciprocal capacity to recognise alternative ones.

Committed to value pluralism, deliberative economists should be prepared to change their values, judgments, theories and assumptions in ways fundamentally different from their preferences. Being deliberative means being more accepting of diverse values and beliefs. DMV then neither accepts any hierarchy, nor acts as an ideological cafeteria in which 'anything goes'.

A structural transformation is called for to return economics to a political economy approach addressing social conflict, a discipline able to question claims by specific interests that their values can be generalised to the rest of society. A viable economics for public policy requires a methodological democratisation, demanding persistent self-critique and deconstruction of claims to truth. Public interest is then defined in terms of a value articulating structure predicated upon a democratised science, one that theorises democratically about the political economy. A truly value plural economic order will only be forthcoming if unconstrained, self-critical norms are actively embraced.

\section{Acknowledgments}

The authors would like to thank John S. Dryzek for providing helpful comments on an earlier draft of this paper.

\section{Notes}

1. A willingness to accept (WTA) compensation could be part of the same procedure but has so far not been employed. In economic welfare theoretic terms this is often the more appropriate measure but has generally been less favoured in stated preference studies for what can only be described as pragmatic and political reasons (see Knetsch, 1994).

2. Values are incommensurable when they cannot be measured in terms of some common cardinal scale of units of value. Neoclassical economics assumes monetary commensurability.

3. Decision aid here refers to cognitive support or guidance beyond the usual small group facilitating measures. 
4. The qualitative focus, however, does not necessarily preclude the use of quantitative survey techniques. Psychometric techniques that allow modelling of the communication of arguments between respondents are acceptable, such as Q methodology, which involves a modified application of factor analysis (Dryzek, 1990).

\section{References}

Aldred, J. (2005) Consumer valuation and citizen deliberation: towards a comparison. In M. Getzner, C. L. Spash and S. Stagl (eds.), Alternatives for Environmental Valuation (pp. 225-243). London, New York: Routledge.

Álvarez-Farizo, B., Gil, J.M. and Howard, B.J. (2009) Impacts from restoration strategies: assessment through valuation workshops. Ecological Economics 68: 787-797.

Álvarez-Farizo, B. and Hanley, N. (2006) Improving the process of valuing non-market benefits: combining citizens' juries with choice modelling. Land Economics 82(3): 465-478.

Álvarez-Farizoa, B., Hanley, N., Barberán, R. and Lázaro, A. (2007) Choice modeling at the "market stall": Individual versus collective interest in environmental valuation. Ecological Economics 60: 743-751.

Bateman, I.J., Burgess, D., Hutchinson, W.G. and Matthews, D.I. (2008) Learning design contingent valuation (LDCV): NOAA guidelines, preference learning and coherent arbitrariness. Journal of Environmental Economics and Management 55: 127-141.

Bohman, J. (1996) Public Deliberation: Pluralism, Complexity, and Democracy. Cambridge, Mass.: MIT Press.

Bohman, J. and Rehg, W. (eds.) (1997) Deliberative Democracy: Essays on Reason and Politics Cambridge, Mass.: MIT Press.

Brown, T.C., Peterson, G.L. and Tonn, B.E. (1995) The values jury to aid natural resource decisions. Land Economics 71(2): 250-260.

Clark, J., Burgess, J. and Harrison, C.M. (2000) "I struggled with this money business": respondents' perspectives on contingent valuation. Ecological Economics 33: 45-62.

Cohen, J. (1989) Deliberative democracy and democratic legitimacy. In A. Hamlin and P. Pettit (eds.), The Good Polity. Oxford: Blackwell.

Dietz, T. (1994) What should we do? Human ecology and collective decision making. Human Ecology Review 1: 301-309.

Dietz, T., Stern, P.C. and Dan, A. (2009) How deliberation affects stated willingness to pay for mitigation of carbon dioxide emissions: an experiment. Land Economics 85(2): 329-347.

Dryzek, J.S. (1990) Discursive Democracy: Politics, Policy, and Political Science. Cambridge: Cambridge University Press.

Dryzek, J.S. (2000) Deliberative Democracy and Beyond: Liberals, Critics, Contestations. Oxford, U.K.: Oxford University Press.

Dryzek, J.S. (2011) Foundations and Frontiers of Deliberative Governance Oxford, U.K.: Oxford University Press.

Douai, A. (2009) Value theory in ecological economics: the contribution of a political economy of wealth. Environmental Values 18: 257-284.

Failing, L., Gregory, R. and Harstone, M. (2007) Integrating science and local knowledge in environmental risk management: a decision-focused approach. Ecological Economics 64: 47-60.

Gregory, R. (2000) Valuing environmental policy options: a case study comparison of multiattribute and contingent valuation survey methods. Land Economics 76(2): 151-173.

Gregory, R., Fischhoff, B. and McDaniels, T. (2005) 'Acceptable inputs: using decision analysis to guide public policy deliberations'. Decision Analysis 2(1): 4-16.

Gregory, R., Lichtenstein, S. and Slovic, P. (1993) Valuing environmental resources: a constructive approach. Journal of Risk and Uncertainty 7: 177-197.

Gregory, R. and Slovic, P. (1997) A constructive approach to environmental valuation. Ecological Economics 21: 175-181. 
Gregory, R. and Wellman, K. (2001) Bringing stakeholder values into environmental policy choices: a community-based estuary case study. Ecological Economics 39(1): 37-52.

Gutmann, A. and Thompson, D. (1996) Democracy and Disagreement Cambridge, Mass.: Belknap Press.

Gutmann, A. and Thompson, D. (2004) Why Deliberative Democracy? Princeton, NJ: Princeton University Press.

Habermas, J.(1984) The Theory of Communicative Action I: Reason and the Rationalization of Society. Boston: Beacon Press.

Hanley, N. and Shogren, J.F. (2005) 'Is cost-benefit analysis anomaly-proof?' Environmental and Resource Economics 32(1): 13-34.

Holland, A. (2002) Are Choices Tradeoffs? In: D.W. Bromley and J. Paavola (eds.), Economics, Ethics, and Environmental Policy: Contested Choices (pp. 17-34). Oxford: Blackwell Publishing.

Howarth, R.B. and Wilson, M.A. (2006) A theoretical approach to deliberative valuation: aggregation by mutual consent. Land Economics 82(1): 1-16.

Ito, N., Takeuchi, K., Kuriyama, K., Shoji, Y., Tsuge, T. and Mitani, Y. (2009) The influence of decisionmaking rules on individual preferences for ecological restoration: evidence from an experimental survey. Ecological Economics 68: 2426-2431.

Jacobs, M. (1997) Environmental valuation, deliberative democracy and public decision-making institutions. In J. Foster (ed.), Valuing Nature?: Ethics, Economics and the Environment. London: Routledge.

James, R. F. and Blamey, R.K. (2005) Deliberation and economic valuation: national park management. In M. Getzner, C.L. Spash and S. Stagl (eds.), Alternatives for Environmental Valuation (pp. 225-243). London, New York: Routledge.

Jorgensen, B.S., Wilson, M.A. and Heberlein, T.A. (2001) Fairness in the contingent valuation of environmental public goods: attitude toward paying for environmental improvements at two levels of scope. Ecological Economics 36: 133-148.

Jorgensen, B. (2009) Social learning and the economic valuation of environmental impacts: a real contribution or a missed opportunity? In J. Martin, M. Rogers and C. Winter (eds.), Climate Change in Regional Australia: Social Learning and Adaptation. Victoria: VURRN Press.

Kahneman, D. and Knetsch, J.L. (1992) 'Valuing public goods: the purchase of moral satisfaction'. Journal of Environmental Economics and Management 22: 57-70.

Kahneman, D., Ritov, I. and Schkade, D. (1999) 'Economic preferences or attitude expressions?: an analysis of dollar responses to public issues'. Journal of Risk and Uncertainty 19(1-3): 203-235.

Keeney, R. (1992) Value-Focused Thinking: A Path to Creative Decisionmaking. Cambridge, Mass.: Harvard University Press.

Knetsch, J.L. (1994) Environmental valuation: some problems of wrong questions and misleading answers. Environmental Values 3(4): 351-368.

Lienhoop, N. and MacMillan, D.C. (2007) Valuing wilderness in Iceland: estimation of WTA and WTP using the market stall approach to contingent valuation. Land Use Policy 24(11): 289-295.

Lo, A.Y. (2011) Analysis and democracy: the antecedents of the deliberative approach of ecosystems valuation. Environment and Planning C 29(6): 958-974.

Macmillan, D.C., Hanley, N. and Lienhoop, N. (2006) Contingent valuation: environmental polling or preference engine? Ecological Economics 60(1): 299-307.

Macmillan, D.C., Philip, L., Hanley, N. and Alvarez-Farizo, B. (2002) Valuing the non-market benefits of wild goose conservation: a comparison of interview and group-based approaches. Ecological Economics 43(1): 49-59.

McDaniels, T.L., Gregory, R. and Fields, D. (1999) Democratizing risk management: successful public involvement in local water management decisions. Risk Analysis 19(3): 497-510.

McDaniels, T.L., Gregory, R., Arvai, J. and Chuenpagde, R. (2003) Decision structuring to alleviate embedding in environmental valuation. Ecological Economics 46: 33-46.

Munda, G. (1995) Multicriteria Evaluation in a Fuzzy Environment. Heidelberg: Physica-Verlag.

Niemeyer, S. and Spash, C. (2001) Environmental valuation analysis, public deliberation, and their pragmatic syntheses: a critical appraisal. Environment and Planning C: Government and Policy 19: $567-585$.

Journal of Economic Surveys (2013) Vol. 27, No. 4, pp. 768-789

(C) 2012 John Wiley \& Sons Ltd 
Norgaard, R.B. (2007) Deliberative economics. Ecological Economics 63: 375-382.

O'Hara, S.U. (1996) Discursive ethics in ecosystems valuation and environmental policy. Ecological Economics 16: 95-107.

O'Hara, S.U. (2001) The challenges of valuation: ecological economics between matter and meaning. In C.J. Cleveland, D.I. Stern and R. Costanza (eds.), The Economics of Nature and the Nature of Economics (pp. 89-110). Cheltenham, UK; Northampton, Mass.: Edward Elgar.

O'Neill, J.F. (2001) Representing people, representing nature, representing the world. Environment and Planning C: Government \& Policy 9: 483-500.

O'Neill, J. (2007) Markets, Deliberation and Environment London: Routledge.

Orr, S.W. (2007) Values, preferences, and the citizen-consumer distinction in cost-benefit analysis. Politics, Philosophy and Economics 6(1): 107-130.

Peterson, G.L., Driver B.L. and Gregory R. (eds). (1988) Amenity Resource Valuation: Integrating Economics with Other Disciplines. State College, PA: Venture Publishing.

Philip, L.J. and MacMillan, D.C. (2005) Exploring values, context and perceptions in contingent valuation studies: the CV market stall technique and willingness to pay for wildlife conservation. Journal of Environmental Planning and Management 48(2): 257-274.

Powe, N.A. (2007) Redesigning Environmental Valuation: Mixing Methods within Stated Preference Techniques Cheltenham, England: Edward Elgar.

Rawls, J. (1971) A Theory of Justice Oxford: Clarendon Press.

Rawls, J. (1997) The idea of public reason revisited. The University of Chicago Law Review 64(3): 765-807.

Robinson, J.J. (2002) Environmental value transfer: an application for the South East Queensland waterways. Water Science and Technology 45(11): 91-100.

Robinson, J.J., Clouston, B., Suh, J. and Chaloupka, M. (2009) Are citizens' juries a useful tool for assessing environmental value? Environmental Conservation 35(4): 351-360.

Sagoff, M.(1988) The Economy of the Earth: Philosophy, Law, and the Environment Cambridge University Press, Cambridge.

Sagoff, M. (1998) Aggregation and deliberation in valuing environmental public goods: a look beyond contingent pricing. Ecological Economics 24: 213-230.

Söderbaum, P. and Brown, J. (2010) Democratizing economics: pluralism as a path toward sustainability. Annals of The New York Academy of Sciences 1185: 179-195.

Spash, C.L. (2000a) Multiple value expression in contingent valuation: economics and ethics. Environmental Science \& Technology 34(8): 1433-1438.

Spash, C.L. (2000b) Ecosystems, contingent valuation and ethics: the case of wetlands re-creation. Ecological Economics 34(2): 195-215.

Spash, C.L. (2001) Broadening democracy in environmental policy processes. Environment \& Planning C: Government \& Policy 19(4): 475-482.

Spash, C.L. (2006) Non-economic motivation for contingent values: rights and attitudinal beliefs in the willingness to pay for environmental improvements. Land Economics 82(4): 602-622.

Spash, C.L. (2007) Deliberative monetary valuation (DMV): issues in combining economic and political processes to value environmental change. Ecological Economics 63(4) 690-699.

Spash, C.L. (2008a) Deliberative monetary valuation and the evidence for a new value theory. Land Economics 84(3): 469-488.

Spash, C.L. (2008b) Contingent valuation design and data treatment: if you can't shoot the messenger, change the message. Environment \& Planning C: Government \& Policy 26(1): 34-53.

Spash, C.L., Stagl, S. and Getzner, M. (2005) Exploring alternatives for environmental valuation. In M. Getzner, C.L. Spash and S. Stagl (eds.) Alternatives for Environmental Valuation. London; New York: Routledge.

Spash, C.L., Urama, K., Burton, R., Kenyon, W., Shannon, P. and Hill, G. (2009) Motives behind willingness to pay for improving biodiversity in a water ecosystem: economics, ethics and social psychology. Ecological Economics 68: 955-964.

Spash, C.L. and Vatn, A. (2006) Transferring environmental value estimates: issues and alternatives. Ecological Economics 60: 379-388.

Stirling, A. (1997) Multi-criteria mapping: mitigating the problems of environmental valuation? In J. Foster (ed.), Valuing Nature?: Ethics, Economics and the Environment (pp. 186-210). London: Routledge.

Journal of Economic Surveys (2013) Vol. 27, No. 4, pp. 768-789

(C) 2012 John Wiley \& Sons Ltd 
Stirling, A. (2006) Analysis, participation and power: justification and closure in participatory multi-criteria analysis. Land Use Policy 23: 95-107.

Urama, K.C. and Hodge, I. (2006) Participatory environmental education and willingness to pay for river basin management: empirical evidence from Nigeria. Land Economics 82(4): 542-561.

Vatn, A. (2005) Institutions and the Environment. Cheltenham, England: Edward Elgar.

Vatn, A. (2009) An institutional analysis of methods for environmental appraisal. Ecological Economics 68: 2207-2215.

Vatn, A. and Bromley, D.W. (1994) Choices without prices without apologies. Journal of Environmental Economics and Management 26: 129-148.

Ward, H. (1999) Citizens' juries and valuing the environment: a proposal. Environmental Politics 8(2): 75-96.

Warren, M.E. (1995) The self in discursive democracy, In S.K. White (ed.), The Cambridge Companion to Habermas (pp. 167-200), Cambridge: Cambridge University Press.

Wilson, M.A. and Howarth, R.B. (2002) Discourse-based valuation of ecosystem services: establishing fair outcomes through group deliberation. Ecological Economics 41: 431-443.

Zografos, C., and Howarth, R.B. (eds.) (2008) Deliberative Ecological Economics. New Delhi: Oxford University Press. 